\title{
A comparative study of quality of life of patients with maxillofacial fracture and healthy controls at two tertiary healthcare institutions
}

\author{
Mayowa Solomon Somoye ${ }^{1}$, Adekunle Moses Adetayo ${ }^{2}$, Wasiu Lanre Adeyemo', \\ Akinola Ladipo Ladeinde ${ }^{1}$, Micah Olalekan Gbotolorun ${ }^{1}$ \\ ${ }^{1}$ Department of Oral \& Maxillofacial Surgery, Lagos University Teaching Hospital, Idi-Araba, \\ ${ }^{2}$ Department of Surgery, Benjamin Carson Snr School of Medicine, Babcock University, Ilisan-Remo, Nigeria
}

\begin{abstract}
J Korean Assoc Oral Maxillofac Surg 2021;47:351-359)
Objectives: Despite treatment, the pre-traumatic facial appearance of patients with maxillofacial fractures might not be able to be restored, and this difference can affect the person's quality of life (QoL). This study was designed to evaluate changes in QoL of people with maxillofacial fractures.

Materials and Methods: The study population was comprised of participants with maxillofacial fracture and age- and sex-matched healthy controls without history of such fracture. QoL was measured using the World Health Organization Quality of Life BREF (WHOQOL-BREF) questionnaire, which was administered to the patients before treatment (Time 1), at 6 weeks post-treatment (Time 2), and at 12 weeks postoperatively (Time 3). The values were compared with those of healthy controls. The QoL was compared between closed reduction group and open reduction and internal fixation group.

Results: The QoL scores of people with maxillofacial fracture before treatment were significantly lower $(P=0.001)$ than those of healthy controls in all domains of the WHOQOL-BREF. The QoL scores in the psychological and social domains of patients with maxillofacial fracture at Time 3 were still lower than those of healthy controls $(P=0.001)$.

Conclusion: The QoL of patients with maxillofacial fracture was significantly reduced before treatment in all domains and remained reduced in both psychological and social domains weeks after treatment. Therefore, clinicians must be aware of and manage the residual psychosocial issues that can accompany the post-treatment period of maxillofacial injury.
\end{abstract}

Key words: Bone fractures, Fixation, Quality of life

[paper submitted 2021. 7. 1 / revised 2021. 8. 24 / accepted 2021. 8. 25]

\section{Introduction}

Maxillofacial fractures are attracting the attention of healthcare professionals worldwide because of their increasing incidence and diverse associated injuries, as well as their association with significant morbidity, disfigurement, loss of function, economic implications, and issues that concern postoperative quality of life $(\mathrm{QoL})^{1,2}$. Despite treatment of maxillofacial fractures, the pre-traumatic facial appearance

\footnotetext{
Adekunle Moses Adetayo

Department of Surgery, Benjamin Carson Snr School of Medicine, Babcock University, PMB 4003, Ilishan-Remo, Ogun, Nigeria

TEL: +234-8038337845

E-mail: adetayoa@babcock.edu.ng

ORCID: https://orcid.org/0000-0002-7318-0810
}

(c) This is an open-access article distributed under the terms of the Creative Commons Attribution Non-Commercial License (http://creativecommons.org/ licenses/by-nc/4.0/), which permits unrestricted non-commercial use, distribution, and reproduction in any medium, provided the original work is properly cited.

Copyright (C) 2021 The Korean Association of Oral and Maxillofacial Surgeons. might not be restored; the resultant facial disfigurement can have both social and psychological consequences ${ }^{3,4}$.

The human face is a vital component of one's personality and body image; a visible disfigurement can have a significant psychological impact upon the individual concerned ${ }^{5}$. According to the World Health Organization (WHO)'s definition of health ${ }^{6}$, optimum health is not achieved until the QoL of the patient is addressed and restored. As a result, treatment of patients with maxillofacial fractures should include assessment of their QoL in relation to patient satisfaction and psychological well-being ${ }^{7}$. A comprehensive healthcare assessment of people with maxillofacial fractures should address QoL because this issue can affect the subjects' overall wellbeing; if these issues are not detected and treated, they can remain long term ${ }^{3}$. Unfortunately, the efficacy of treatment of maxillofacial fractures by reduction and fixation is based on clinical normative indicators alone, and QoL assessment of people with maxillofacial fractures is not performed routinely 
in clinical practice.

There are several satisfactory ways of measuring the wellbeing and QoL of patients ${ }^{8}$. The Sickness Impact Profile developed by Klonoff et al. ${ }^{9}$; the General Oral Health Assessment Index introduced by Atchison and Dolan ${ }^{10}$; the Life Satisfaction Index-A described by Webb et al. ${ }^{11}$; and the Short Form 36 (SF-36) created by Findler et al. ${ }^{12}$ have all been used as measures of well-being and QoL. The WHO's Quality of Life (WHOQOL-100) and its abridged version, the WHOQOL-BREF, which can be used in a variety of cultural settings, is the most widely employed inventory ${ }^{13}$. The WHOQOL-BREF contains two items from the Overall Quality of Life and General Health section and one item from each of the remaining 24 facets included in the WHOQOL-100, leading to a total of 26 items. All items are rated on five-point scale. On the WHOQOL-BREF, Domains 1 and 3 and 2 and 6 of the WHOQOL-100 were merged, resulting in an instrument with four domains of (1) physical health, (2) psychological, (3) social relationships, and (4) enviroment. The WHOQOL-BREF is popular since its brevity reduces the patient response burden and facilitates its use in conjunction with other measures. This inventory has been used in Nigeria $^{14}$ and was administered in the present study. This short QoL assessment tool is a generic measure designed for use within a wide range of psychological and physical disorders. It contains 26 questions and uses a five-point Likert-type response scale ${ }^{14}$. For this study, a four-domain model was applied.(Appendices 1, 2)

QoL studies that have compared Nigerian patients with maxillofacial fractures with healthy control participants are rare. The present study will provide surgeons with a better understanding of the impact of maxillofacial fractures on the QoL of patients and equip surgeons with a method to assess the efficacy of treatment that is based not only on clinical correlates, but also on QoL assessment. As a result, surgeons can pay equal attention to reduction and fixation of maxillofacial fractures and the evolving QoL challenges that follow maxillofacial fracture.

\section{Materials and Methods}

This was a prospective and comparative study of the QoL of patients with maxillofacial fracture and that of healthy controls who presented between April and December 2015, to the Department of Oral and Maxillofacial Surgery at Lagos University Teaching Hospital, Idi-Araba, Lagos, and Lagos State University Teaching Hospital, Ikeja, Lagos. Ethical approval was obtained from the Health Research and Ethics Committees of both centers (ADM/DCST/HREC/1425 and LREC/10/06/522, respectively), and informed consent was provided by all participants.

A sample size calculation formula adapted from the study of Ukpong et al. ${ }^{14}$ was used to compare the means of the maxillofacial fracture patients and controls to give a sample size of 47 , including an attrition rate of $10 \%$, for both groups. The patients who presented with middle and lower third fracture, within 48 hours of injury, who were at least 18 years of age, and gave their consent were included in the study, while people who presented with upper third fracture, at more than 48 hours after injury, had infected fracture or other associated injuries located outside the maxillofacial region, or were mentally handicapped, unconscious, or could neither read nor write were excluded from the study.

The comparative group of healthy controls that were sexand age-matched to the study participants were recruited from the family members of the patients who were present at the initial presentation (Time 1). These people gave their consent to participate in the study and volunteered to be present at the later times of data collection.

Socio-demographic data (including age, gender, educational status, employment status, and marital status) and clinical data including etiology of fracture, site of fracture, type of fracture, type of treatment (closed reduction or open reduction and internal fixation [ORIF]) and Glasgow coma score at presentation were collected using a structured questionnaire. Facial fractures were classified as located in the upper third, middle third, or lower third of the face. The fractures were classified further based on the specific bone affected (e.g., mandible, maxilla).

The QoL of the patients and those of the controls was measured using the WHOQOL-BREF questionnaire at presentation, before treatment (Time 1), at 6 weeks post-treatment (Time 2), and at 12 weeks postoperatively (Time 3 ) for both closed reduction and ORIF cases. The postoperative values were compared with those of the healthy controls and with the QoL scores (Time 1) before treatment. In addition, the QoL was compared between the two treatment groups (closed reduction and ORIF).

After item recording and handling of missing data, a raw score was computed from a simple algebraic sum of all items in each of the four domains as follows:

Physical health domain=

$$
\text { ([6-Q3]+[6-Q4]+Q5+Q6+Q7+Q8+Q9) }
$$

Psychological domain $=$ 
$(\mathrm{Q} 10+\mathrm{Q} 11+\mathrm{Q} 12+\mathrm{Q} 13+[6-\mathrm{Q} 14]+15)$

Social relationships domain $=(\mathrm{Q} 16+\mathrm{Q} 18+\mathrm{Q} 19)$

Environment domain=

$$
\text { (Q20+Q21+Q22+Q23+Q24+Q25+Q26) }
$$

The next step was to convert the raw domain score to a transformed score on a scale of 0-100 using the following information:

DOMAIN 1=physical health domain; DOMAIN 2=psychological domain; DOMAIN 3=social relationships domain; DOMAIN 4=environment domain.

For example, the transformed score on a scale from 0-100 for an individual with a raw domain score of 22 in the physical health domain (DOMAIN 1) would be 56. Higher transformed scores in a particular domain denote high QoL, and low scores denote low QoL.

Data were entered and analyzed using the IBM SPSS Statistics (ver. 19; IBM, Armonk, NY, USA). Percentages, mean, and standard deviation of numerical variables were determined. The chi-square test, $t$-test, and $\mathrm{F}$ test (ANOVA) were used in the analysis. The confidence interval was set at $95 \%$ for all statistical tests, the results of which were considered significant when $P$-value was $<0.05$.

\section{Results}

Fifty people with maxillofacial fracture participated in this study. There were 43 males $(86.0 \%)$ and 7 females $(14.0 \%)$

Table 1. Pattern of occurrence of maxillofacial fractures $(n=50)$

\begin{tabular}{lc}
\hline \multicolumn{1}{c}{ Variable } & $\mathrm{n}(\%)$ \\
\hline Mandibular fracture alone & $34(68.0)$ \\
Le Fort fracture alone (unilateral) & $2(4.0)$ \\
Zygomatic complex fracture alone (left, 6; right, 1) & $7(14.0)$ \\
Mandibular and Le Fort fractures & $1(2.0)$ \\
Mandibular and zygomatic complex fractures & $4(8.0)$ \\
Mandibular, Le Fort, and zygomatic arch fractures & $1(2.0)$ \\
Le Fort and naso-orbito-ethmoidal fractures & $1(2.0)$ \\
\hline
\end{tabular}

Mayowa Solomon Somoye et al: A comparative study of quality of life of patients with maxillofacial fracture and healthy controls at two tertiary healthcare institutions. J Korean Assoc Oral Maxillofac Surg 2021 with a male-to-female ratio of 6.1 to 1 . The mean age of the patients was $32.4 \pm 11.6$ years (range, 19-66 years), while the mean age of the control participants was $32.4 \pm 11.6$ years (range, 19-66 years). The most commonly affected age group was the third decade $(27 / 50,54.0 \%)$ of life, followed by the fourth decade $(12 / 50,24.0 \%)$.

\section{Pattern of occurrence of maxillofacial fractures}

Isolated mandibular fracture $(68.0 \%)$ was the most common maxillofacial fracture, followed by isolated zygomatic complex fracture $(14.0 \%)$; isolated Le Fort fracture $(2.0 \%)$ was the least common type. Overall, 40 patients sustained mandibular fractures, 5 had Le Fort fractures, 11 sustained zygomatic complex fractures, 1 had a zygomatic arch fracture, and 1 experienced a naso-orbito-ethmoidal fracture. Seven participants presented with fractures involving more than one bone. Forty-one subjects $(82.0 \%)$ also were diagnosed with related soft tissue injury, with laceration being the most common $(61.0 \%)$, followed by contusion $(41.5 \%)$ and avulsion (4.9\%).(Table 1) Twenty-nine (58.0\%) patients were treated with closed reduction, while 21 (42.0\%) underwent ORIF.(Table 2)

\section{Quality of life (patient vs control)}

Table 3 shows the mean QoL scores of participants with maxillofacial fracture at presentation. The mean overall QoL score was 1.74 \pm 0.53 , while the mean QoL score for the psychological domain, which was the highest score, was

Table 2. Types of maxillofacial fracture treatments $(n=50)$

\begin{tabular}{lc}
\hline \multicolumn{1}{c}{ Types of treatment } & $\mathrm{n}(\%)$ \\
\hline Closed reduction & $29(58.0)$ \\
Open reduction and internal fixation & $21(42.0)$ \\
\hline
\end{tabular}

Mayowa Solomon Somoye et al: A comparative study of quality of life of patients with maxillofacial fracture and healthy controls at two tertiary healthcare institutions. J Korean Assoc Oral Maxillofac Surg 2021

Table 3. The mean difference in perceived quality of life between patient (before treatment at Time 1) and control groups

\begin{tabular}{lcrrr}
\hline \multicolumn{1}{c}{ Variable } & Patient $(\mathrm{n}=50)$ & Control $(\mathrm{n}=50)$ & $t$ & \multicolumn{1}{c}{$P$-value } \\
\hline Overall quality of life & $1.74 \pm 0.53$ & $3.96 \pm 0.40$ & 23.68 & 0.001 \\
Overall quality of health & $1.74 \pm 0.57$ & $4.68 \pm 0.51$ & 27.26 & 0.001 \\
Physical health domain & $31.50 \pm 9.20$ & $82.70 \pm 6.60$ & 32.02 & 0.001 \\
Psychological domain & $34.40 \pm 15.10$ & $84.80 \pm 6.60$ & 21.60 & 0.001 \\
Social relationships domain & $23.00 \pm 6.60$ & $64.40 \pm 8.10$ & 9.66 & 0.001 \\
Environment domain & $29.30 \pm 6.60$ & $65.60 \pm 7.00$ & 26.62 & 0.001 \\
\hline
\end{tabular}

Values are presented as mean \pm standard deviation.

Mayowa Solomon Somoye et al: A comparative study of quality of life of patients with maxillofacial fracture and healthy controls at two tertiary healthcare institutions. J Korean Assoc Oral Maxillofac Surg 2021 
$34.40 \pm 15.10$. The domain with the lowest score was the social relationships domain at $23.00 \pm 6.60$. Table 3 also shows the mean 3.96 \pm 0.40 QoL score of healthy controls without maxillofacial fracture. The QoL was significantly lower for patients with maxillofacial fracture before treatment than it was for healthy controls in all domains of the WHOQOL-

\section{BREF.(Table 3)}

The QoL scores of participants with maxillofacial fracture after treatment were higher in all domains of the WHOQOLBREF at 12 weeks after treatment than those at 6 weeks, although the latter scores were higher than those obtained before treatment.(Tables 4-6) At 12 weeks after treatment, no

Table 4. The mean difference in perceived quality of life of patients with maxillofacial fracture before treatment (Time 1) and six weeks after treatment (Time 2)

\begin{tabular}{lccrc}
\hline \multicolumn{1}{c}{ Variable } & Before treatment & Six weeks after treatment & Paired $t$ & $P$-value \\
\hline Overall quality of life & $1.74 \pm 0.52$ & $2.74 \pm 1.21$ & 6.002 & 0.001 \\
Overall quality of health & $1.74 \pm 0.56$ & $3.08 \pm 0.97$ & 9.092 & 0.001 \\
Physical health domain & $31.50 \pm 9.20$ & $64.88 \pm 12.69$ & 16.310 & 0.001 \\
Psychological domain & $34.40 \pm 15.10$ & $65.62 \pm 11.87$ & 13.967 & 0.001 \\
Social relationships domain & $23.04 \pm 6.68$ & $44.88 \pm 5.96$ & 13.030 & 0.001 \\
Environment domain & $29.28 \pm 6.65$ & $49.36 \pm 12.51$ & 12.709 & 0.001 \\
\hline
\end{tabular}

Values are presented as mean \pm standard deviation.

Mayowa Solomon Somoye et al: A comparative study of quality of life of patients with maxillofacial fracture and healthy controls at two tertiary healthcare institutions. J Korean Assoc Oral Maxillofac Surg 2021

Table 5. The mean difference in perceived quality of life of patients with maxillofacial fracture before treatment (Time 1$)$ and at 12 weeks after treatment (Time 3)

\begin{tabular}{lcccc}
\hline \multicolumn{1}{c}{ Variable } & Before treatment & Twelve weeks after treatment & Paired $t$ & $P$-value \\
\hline Overall quality of life & $1.74 \pm 0.52$ & $4.10 \pm 0.58$ & 20.807 & 0.001 \\
Overall quality of health & $1.74 \pm 0.56$ & $4.60 \pm 0.70$ & 24.271 & 0.001 \\
Physical health domain & $31.50 \pm 9.20$ & $83.36 \pm 5.81$ & 31.829 & 0.001 \\
Psychological domain & $34.42 \pm 15.10$ & $74.30 \pm 7.16$ & 20.448 & 0.001 \\
Social relationships domain & $23.04 \pm 6.68$ & $57.79 \pm 5.96$ & 26.408 & 0.001 \\
Environment domain & $29.28 \pm 6.65$ & $62.72 \pm 6.89$ & 32.635 & 0.001 \\
\hline
\end{tabular}

Values are presented as mean \pm standard deviation.

Mayowa Solomon Somoye et al: A comparative study of quality of life of patients with maxillofacial fracture and healthy controls at two tertiary healthcare institutions. $J$ Korean Assoc Oral Maxillofac Surg 2021

Table 6. The mean difference in perceived quality of life of patients with maxillofacial fracture at six weeks (Time 2) and 12 weeks after treatment (Time 3)

\begin{tabular}{|c|c|c|c|c|}
\hline Variable & Six weeks after treatment & Twelve weeks after treatment & Paired $t$ & $P$-value \\
\hline Overall quality of life & $2.74 \pm 1.21$ & $4.10 \pm 0.58$ & 6.681 & 0.001 \\
\hline Overall quality of health & $3.08 \pm 0.97$ & $4.60 \pm 0.70$ & 8.603 & 0.001 \\
\hline Physical health domain & $64.88 \pm 12.69$ & $83.36 \pm 5.81$ & 10.286 & 0.001 \\
\hline Psychological domain & $65.62 \pm 11.87$ & $74.30 \pm 7.16$ & 7.666 & 0.001 \\
\hline Social relationships domain & $44.88 \pm 5.96$ & $57.79 \pm 5.96$ & 6.423 & 0.001 \\
\hline Environment domain & $49.36 \pm 12.51$ & $62.72 \pm 6.89$ & 9.045 & 0.001 \\
\hline
\end{tabular}

Values are presented as mean \pm standard deviation.

Mayowa Solomon Somoye et al: A comparative study of quality of life of patients with maxillofacial fracture and healthy controls at two tertiary healthcare institutions. J Korean Assoc Oral Maxillofac Surg 2021

Table 7. The mean difference in perceived quality of life between patients with maxillofacial fracture at 12 weeks after treatment (Time 3 ) and in the control group

\begin{tabular}{lcrrr}
\hline \multicolumn{1}{c}{ Variable } & Study $(\mathrm{n}=50)$ & Control $(\mathrm{n}=50)$ & $t$ & $P$-value \\
\hline Overall quality of life & $4.10 \pm 0.58$ & $3.96 \pm 0.40$ & 1.402 & 0.164 \\
Overall quality of health & $4.60 \pm 0.70$ & $4.68 \pm 0.51$ & 0.652 & 0.516 \\
Physical health domain & $83.36 \pm 5.81$ & $82.70 \pm 6.60$ & 7.548 & 0.585 \\
Psychological domain & $74.30 \pm 7.16$ & $84.80 \pm 6.60$ & 5.272 & 0.001 \\
Social relationships domain & $57.79 \pm 5.96$ & $65.40 \pm 8.10$ & 2.101 & 0.001 \\
Environment domain & $62.72 \pm 6.90$ & 0.038 &
\end{tabular}

Values are presented as mean \pm standard deviation.

Mayowa Solomon Somoye et al: A comparative study of quality of life of patients with maxillofacial fracture and healthy controls at two tertiary healthcare institutions. J Korean Assoc Oral Maxillofac Surg 2021 
statistically significant difference was found in overall QoL; overall quality of health; QoL in the physical health domain or in the environmental domain between treatment and control groups.(Table 7) However, at 12 weeks after treatment, the QoL scores in the psychological and social relationships domains of patients with maxillofacial fracture were significantly lower than those of the control participants.(Table 7)

\section{Quality of life (closed reduction vs ORIF)}

At 6 weeks after treatment, the QoL scores of participants who underwent ORIF were higher in all domains of the WHOQOL-BREF than were those of patients who underwent closed reduction.(Table 8) At 12 weeks after treatment, there was no statistically significant difference in QoL of people who underwent ORIF or closed reduction.(Table 9)

\section{Discussion}

QoL has been established as an important tool for evaluating the impact of a health condition as well as assessing the efficacy of treatments and health outcomes in people with surgically treatable conditions ${ }^{14,15}$.

In this study, the QoL scores of patients with maxillofacial fracture before treatment (Time 1) were poor in all domains of the WHOQOL-BREF; this finding was in agreement with previous studies ${ }^{3,4}$. The social relationships domain had a minimal score. One very common social response by the public to facial disfigurement is staring and social avoidance $^{16}$. Similarly, the most common reaction by an individual with a disfiguring maxillofacial injury is to withdraw from social interaction. Consequently, the individual's personal relationships are negatively affected, which is reflected in the QoL score ${ }^{17}$. The dysfunction and disfigurement caused by maxillofacial injuries can affect adversely a person's ability to undertake daily activities, such as personal interaction and recreation, and also can lower their mood and self-esteem. These effects interfere with their social relationships and ultimately affect their $\mathrm{QoL}^{14}$. Individuals with disfiguring facial fractures are less attractive and have been found to experience less fulfilling sexual encounters ${ }^{18,19}$. Lento et al. ${ }^{4}$ concluded that lack of supportive social relationships with family and friends can affect both physical and emotional well-being and lead to reduced $\mathrm{QoL}^{4}$.

Compared with the healthy controls, the QoL scores of patients with maxillofacial fracture at presentation were low in all domains. This result was in agreement with the works of Ukpong et al. ${ }^{14}$ and Braimah et al. ${ }^{19}$. The psychological domain had the highest score in both groups, although the scores were significantly lower in patients with maxillofacial fracture. The psychological domain of the WHOQOL-BREF contains items that assess acceptability of bodily appear-

Table 8. The mean difference in perceived quality of life between patients that had closed reduction or open reduction and internal fixation (ORIF) 6 weeks after treatment (Time 2)

\begin{tabular}{lcrrr}
\hline \multicolumn{1}{c}{ Variable } & Closed reduction $(\mathrm{n}=29)$ & ORIF $(\mathrm{n}=21)$ & $t$ & $P$-value \\
\hline Overall quality of life & $1.97 \pm 0.87$ & $3.81 \pm 0.68$ & 8.113 & 0.001 \\
Overall quality of health & $2.59 \pm 0.83$ & $3.76 \pm 0.70$ & 5.293 & 0.001 \\
Physical health domain & $56.31 \pm 6.65$ & $76.71 \pm 9.27$ & 9.299 & 0.001 \\
Psychological domain & $58.03 \pm 8.25$ & $70.62 \pm 7.85$ & 7.590 & 0.001 \\
Social relationships domain & $44.34 \pm 5.27$ & $55.62 \pm 6.87$ & 5.734 & 0.001 \\
Environment domain & $41.52 \pm 8.82$ & $58.19 \pm 7.87$ & 7.725 & 0.001 \\
\hline
\end{tabular}

Values are presented as mean \pm standard deviation.

Mayowa Solomon Somoye et al: A comparative study of quality of life of patients with maxillofacial fracture and healthy controls at two tertiary healthcare institutions. J Korean Assoc Oral Maxillofac Surg 2021

Table 9. The mean difference in perceived quality of life between patients that had closed reduction or open reduction and internal fixation (ORIF) at 12 weeks after treatment (Time 3)

\begin{tabular}{lcrrr}
\hline \multicolumn{1}{c}{ Variable } & Closed reduction $(\mathrm{n}=29)$ & ORIF $(\mathrm{n}=21)$ & $t$ & $P$-value \\
\hline Overall quality of life & $4.17 \pm 0.71$ & $4.00 \pm 0.32$ & 1.038 & 0.305 \\
Overall quality of health & $4.66 \pm 0.77$ & $4.52 \pm 0.60$ & 0.651 & 0.518 \\
Physical health domain & $82.79 \pm 6.18$ & $84.14 \pm 5.29$ & 0.808 & 0.423 \\
Psychological domain & $71.45 \pm 6.60$ & $73.24 \pm 6.04$ & 3.719 & 0.413 \\
Social relationships domain & $54.43 \pm 5.27$ & $57.62 \pm 6.87$ & 0.743 & 0.461 \\
Environment domain & $60.10 \pm 6.34$ & $62.33 \pm 6.04$ & 3.499 & 0.381 \\
\hline
\end{tabular}

Values are presented as mean \pm standard deviation.

Mayowa Solomon Somoye et al: A comparative study of quality of life of patients with maxillofacial fracture and healthy controls at two tertiary healthcare institutions. J Korean Assoc Oral Maxillofac Surg 2021 
ance and negative feelings such as anxiety, depression, and despair. Anxiety and depression are strongly associated with maxillofacial fracture and can produce post-traumatic stress disorder (PTSD) symptoms that have adverse effects on body image, self-esteem, and $\mathrm{QoL}^{7,20}$. Shepherd ${ }^{7}$ and Bisson et al. ${ }^{20}$ have documented that anxiety and depression are associated with facial trauma. Shepherd ${ }^{7}$ reported that anxiety, depression, and psychologic distress often develop in patients within three months of mandibular fracture, and the resultant scarring of the associated soft tissue injuries can serve as a constant reminder of the traumatic event. Bisson et al. ${ }^{20}$ found that patients who experienced facial fracture had a $27 \%$ greater likelihood of developing PTSD by seven weeks posttrauma. Anxiety and depression are associated with maxillofacial fracture and can lead to a reduced QoL $\mathrm{L}^{7,14,18,20}$.

The patients with maxillofacial fracture in the present study experienced improvement in all domains of the WHOQOLBREF over the postoperative review period, with the greatest improvement noted at the 12-week review (Time 3). This finding is in close agreement with the results of other studies $^{7,14,19,20}$. At Time 3, healing had progressed satisfactorily with restoration and correction of the facial profile, and most of the participants had returned to work and normal daily activities.

At Time 2 (6 weeks after treatment), the QoL scores of patients who underwent closed reduction were lower than the scores of participants who underwent ORIF in all domains of the WHOQOL-BREF. This outcome is consistent with a previous study ${ }^{21}$. This finding could be attributed to psychological and social effects in people treated with closed reduction, which can limit choice of food, leading to weight loss; poor oral hygiene; decreased social interaction; and absenteeism at work. This was not the case with participants who underwent ORIF, who experienced fewer limitations on their activities after treatment.

There was no difference in overall QoL at Time 3 of patients who received closed reduction or ORIF. This result agrees with the work of Omeje et al. ${ }^{22}$. The lack of difference between the treatment modalities regarding patient overall QoL might be related to the absence of interfragmentary mobility in both groups, which can cause non-union, mal-union, and possible infection and reduces QoL. ORIF limits interfragmentary mobility during function, while closed reduction limits masticatory function of the mandible and interfragmentary mobility ${ }^{22}$. This lack of difference also could be attributed to patient compliance with post-operative instructions in both groups, which led to more favorable outcomes ${ }^{22}$.
This finding also can be explained by removal of the arch bars and wires used in closed reduction, allowing patients to eat a wider variety of food and open their mouths, affecting weight and social interaction.

Despite the treatment of patients with maxillofacial fracture and the significant improvement in QoL in all domains over the treatment period, the patient QoL scores in the psychological and social relationships domains at 9 weeks after treatment were lower than those of the healthy controls. This result supports the work of previous researchers who reported that individuals treated for maxillofacial fracture had lower QoL score in both psychological and social relationships domains compared with healthy controls ${ }^{4,14,20,23}$. The resultant facial disfigurement that can occur following maxillofacial fracture and its associated soft tissue injuries can lead to social and psychological consequences ${ }^{3}$. The presence of any scarring in the associated soft tissue injuries can act as a constant reminder of the traumatic event and can have both psychological and social consequences, even after treatment.

\section{Conclusion}

The QoL scores of patients with maxillofacial fracture before treatment were significantly lower than those of healthy controls in all domains of the WHOQOL-BREF. The QoL scores of patients with maxillofacial fracture at Time 3 were lower than those of healthy controls in the psychological and social domains. In view of this finding, practitioners must be aware of possible residual psychological and social relationship issues that can accompany the posttraumatic period of maxillofacial fracture. Such patients must be referred to psychologists or psychiatrists for further evaluation and management.

\section{ORCID}

Mayowa Solomon Somoye, https://orcid.org/0000-00030715-5788

Adekunle Moses Adetayo, https://orcid.org/0000-00027318-0810

Wasiu Lanre Adeyemo, https://orcid.org/0000-0002-02577853

Akinola Ladipo Ladeinde, https://orcid.org/0000-00025940-2958

Micah Olalekan Gbotolorun, https://orcid.org/0000-0002$5375-4530$ 


\section{Authors' Contributions}

M.S.S. was involved in the conception, planning, data collection, interpretation, analysis, and writing of the final manuscript. A.M.A. was involved in the statistical study planning, analysis, data interpretation, and writing of the final manuscript. W.L.A. was involved in study planning, data interpretation, and writing of the final manuscript. A.L.L. was involved in the data interpretation and writing of the final manuscript. M.O.G. was involved in the planning and writing of the final manuscript.

\section{Ethics Approval and Consent to Participate}

Ethical approval was obtained from the Health Research and Ethics Committees of both centers (ADM/DCST/ HREC/1425 and LREC/10/06/522, respectively), and informed consent was provided by all participants.

\section{Conflict of Interest}

No potential conflict of interest relevant to this article was reported.

\section{References}

1. Adekeye EO. The pattern of fractures of the facial skeleton in Kaduna, Nigeria. A survey of 1,447 cases. Oral Surg Oral Med Oral Pathol 1980;49:491-5. https://doi.org/10.1016/00304220(80)90068-7

2. Kieser J, Stephenson S, Liston PN, Tong DC, Langley JD. Serious facial fractures in New Zealand from 1979 to 1998. Int J Oral Maxillofac Surg 2002;31:206-9. https://doi.org/10.1054/ijom.2002.0208

3. Holbrook TL, Hoyt DB. The impact of major trauma: quality-oflife outcomes are worse in women than in men, independent of mechanism and injury severity. J Trauma 2004;56:284-90. https:// doi.org/10.1097/01.TA.0000109758.75406.F8

4. Lento J, Glynn S, Shetty V, Asarnow J, Wang J, Belin TR. Psychologic functioning and needs of indigent patients with facial injury: a prospective controlled study. J Oral Maxillofac Surg 2004;62:92532. https://doi.org/10.1016/j.joms.2004.02.009

5. De Sousa A. Psychological issues in acquired facial trauma. Indian J Plast Surg 2010;43:200-5. https://doi.org/10.4103/09700358.73452

6. World Health Organization (WHO). WHO definition of health, preamble to the constitution of the World health Organization as adopted by the International Health Conference. New York (NY): WHO; 1946:19-22.

7. Shepherd J. Victims of personal violence: the relevance of Symonds' model of psychological response and loss-theory. Br J Soc Work 1990;20:309-32.

8. Tubert-Jeannin S, Riordan PJ, Morel-Papernot A, Porcheray S, Saby-Collet S. Validation of an oral health quality of life index (GOHAI) in France. Community Dent Oral Epidemiol 2003;31:275-84. https://doi.org/10.1034/j.1600-0528.2003.t01-1-00006.x
9. Klonoff PS, Snow WG, Costa LD. Quality of life in patients 2 to 4 years after closed head injury. Neurosurgery 1986;19:735-43. https://doi.org/10.1227/00006123-198611000-00004

10. Atchison KA, Dolan TA. Development of the Geriatric Oral Health Assessment Index. J Dent Educ 1990;54:680-7.

11. Webb CR, Wrigley M, Yoels W, Fine PR. Explaining quality of life for persons with traumatic brain injuries 2 years after injury. Arch Phys Med Rehabil 1995;76:1113-9. https://doi.org/10.1016/s00039993(95)80118-9

12. Findler M, Cantor J, Haddad L, Gordon W, Ashman T. The reliability and validity of the SF-36 health survey questionnaire for use with individuals with traumatic brain injury. Brain Inj 2001;15:71523. https://doi.org/10.1080/02699050010013941

13. Krägeloh CU, Henning MA, Hawken SJ, Zhao Y, Shepherd D, Billington R. Validation of the WHOQOL-BREF quality of life questionnaire for use with medical students. Educ Health (Abingdon) 2011;24:545.

14. Ukpong DI, Ugboko VI, Ndukwe KC, Gbolahan OO. Health-related quality of life in Nigerian patients with facial trauma and controls: a preliminary survey. Br J Oral Maxillofac Surg 2008;46:297300. https://doi.org/10.1016/j.bjoms.2007.09.013

15. Stone MB, Botto LD, Feldkamp ML, Smith KR, Roling L, Yamashiro D, et al. Improving quality of life of children with oral clefts: perspectives of parents. J Craniofac Surg 2010;21:1358-64. https://doi.org/10.1097/SCS.0b013e3181ec6872

16. Bull R, Rumsey N. The social psychology of facial appearance. New York (NY): Springer-Verlag; 1988:9-39.

17. Neale HW, Billmire DA, Carey JP. Reconstruction following head and neck burns. Clin Plast Surg 1986;13:119-36.

18. Levine E, Degutis L, Pruzinsky T, Shin J, Persing JA. Quality of life and facial trauma: psychological and body image effects. Ann Plast Surg 2005;54:502-10. https://doi.org/10.1097/01. sap.0000155282.48465.94

19. Braimah RO, Ukpong DI, Ndukwe KC. Psychosocial and HealthRelated Quality of Life (HRQoL) aspect of oral and maxillofacial trauma. In: Almasri MA, Kummoona R, eds. Maxillofacial surgery and craniofacial deformity: practices and updates. London: IntechOpen; 2020:449.

20. Bisson JI, Shepherd JP, Dhutia M. Psychological sequelae of facial trauma. J Trauma 1997;43:496-500. https://doi. org/10.1097/00005373-199709000-00018

21. Shetty V, Dent DM, Glynn S, Brown KE. Psychosocial sequelae and correlates of orofacial injury. Dent Clin North Am 2003;47:141-57, xi. https://doi.org/10.1016/s0011-8532(02)000599

22. Omeje KU, Rana M, Adebola AR, Efunkoya AA, Olasoji HO, Purcz N, et al. Quality of life in treatment of mandibular fractures using closed reduction and maxillomandibular fixation in comparison with open reduction and internal fixation--a randomized prospective study. J Craniomaxillofac Surg 2014;42:1821-6. https:// doi.org/10.1016/j.jcms.2014.06.021

23. Hull AM, Lowe T, Devlin M, Finlay P, Koppel D, Stewart AM. Psychological consequences of maxillofacial trauma: a preliminary study. Br J Oral Maxillofac Surg 2003;41:317-22. https://doi. org/10.1016/s0266-4356(03)00131-1

How to cite this article: Somoye MS, Adetayo AM, Adeyemo WL, Ladeinde AL, Gbotolorun MO. A comparative study of quality of life of patients with maxillofacial fracture and healthy controls at two tertiary healthcare institutions. J Korean Assoc Oral Maxillofac Surg 2021;47:351-359. https://doi.org/10.5125/ jkaoms.2021.47.5.351 
Appendix 1. World Health Organization Quality of Life BREF (WHOQOL-BREF) domains and facets

Domain

1. Physical health

2. Psychological

3.Social relationships

4. Environment
Facets incorporated within domain

Activities of daily living

Dependence on medical substances and medical aids

Energy and fatigue

Mobility

Pain and discomfort

Sleep and rest

Work capacity

Bodily image and appearance

Negative feelings

Positive feelings

Self-esteem

Spirituality/religion/personal believes

Thinking, learning, memory and concentration

Personal relationship

Social support

Social activity

Financial resources

Freedom, physical safety and security

Health and social care: accessibility and quality

Home environment

Opportunities for acquiring new information and skills

Participation in and opportunities for recreation/leisure activities

Physical environment (pollution/noise/traffic/climate)

Transport

Mayowa Solomon Somoye et al: A comparative study of quality of life of patients with maxillofacial fracture and healthy controls at two tertiary healthcare institutions. J Korean Assoc Oral Maxillofac Surg 2021 
Appendix 2. World Health Organization Quality of Life BREF (WHOQOL-BREF) questions

\begin{tabular}{|c|c|c|c|c|c|c|}
\hline & & Very poor & Poor & $\begin{array}{l}\text { Neither poor } \\
\text { nor good }\end{array}$ & Good & Very good \\
\hline \multirow[t]{2}{*}{1} & How would you rate your quality of life? & 1 & 2 & 3 & 4 & 5 \\
\hline & & $\begin{array}{c}\text { Very } \\
\text { dissatisfied }\end{array}$ & Dissatisfied & $\begin{array}{l}\text { Neither satisfied } \\
\text { nor dissatisfied }\end{array}$ & Satisfied & Very satisfied \\
\hline \multirow[t]{2}{*}{2} & How satisfied are you with your health? & 1 & 2 & 3 & 4 & 5 \\
\hline & & Not at all & A little & $\begin{array}{l}\text { A moderate } \\
\text { amount }\end{array}$ & Very much & $\begin{array}{l}\text { An extreme } \\
\text { amount }\end{array}$ \\
\hline 3 & $\begin{array}{l}\text { How much do you feel that pain prevents you } \\
\text { from doing what you need to do? }\end{array}$ & 1 & 2 & 3 & 4 & 5 \\
\hline 4 & $\begin{array}{l}\text { How much do you need medical treatment to } \\
\text { function in your daily life? }\end{array}$ & 1 & 2 & 3 & 4 & 5 \\
\hline \multirow[t]{2}{*}{5} & How much do you enjoy life? & 1 & 2 & 3 & 4 & 5 \\
\hline & & Not at all & A little & $\begin{array}{l}\text { A moderate } \\
\text { amount }\end{array}$ & Very much & Extremely \\
\hline 6 & $\begin{array}{l}\text { To what extent do you feel life to be } \\
\text { meaningful? }\end{array}$ & 1 & 2 & 3 & 4 & 5 \\
\hline 7 & How well are you able to concentrate? & 1 & 2 & 3 & 4 & 5 \\
\hline 8 & How safe do you feel in your daily life? & 1 & 2 & 3 & 4 & 5 \\
\hline \multirow[t]{2}{*}{9} & How healthy is your physical environment? & 1 & 2 & 3 & 4 & 5 \\
\hline & & Not at all & A little & Moderately & Mostly & Completely \\
\hline 10 & Do you have enough energy for everyday life? & 1 & 2 & 3 & 4 & 5 \\
\hline 11 & Are you able to accept your bodily appearance? & 1 & 2 & 3 & 4 & 5 \\
\hline 12 & $\begin{array}{l}\text { To what extent do you have enough money to } \\
\text { meet your needs? }\end{array}$ & 1 & 2 & 3 & 4 & 5 \\
\hline 13 & $\begin{array}{l}\text { How available to you is the information that you } \\
\text { need in your day-to-day life? }\end{array}$ & 1 & 2 & 3 & 4 & 5 \\
\hline 14 & $\begin{array}{l}\text { To what extent do you have the opportunity for } \\
\text { leisure activities? }\end{array}$ & 1 & 2 & 3 & 4 & 5 \\
\hline
\end{tabular}

\begin{tabular}{|c|c|c|c|c|c|c|}
\hline & & Very poor & Poor & $\begin{array}{l}\text { Neither poor } \\
\text { nor good }\end{array}$ & Good & Very good \\
\hline \multirow[t]{2}{*}{15} & How well are you able to get around? & 1 & 2 & 3 & 4 & 5 \\
\hline & & $\begin{array}{c}\text { Very } \\
\text { dissatisfied }\end{array}$ & Dissatisfied & $\begin{array}{c}\text { Neither satisfied } \\
\text { nor dissatisfied }\end{array}$ & Satisfied & Very satisfied \\
\hline 16 & How satisfied are you with your sleep? & 1 & 2 & 3 & 4 & 5 \\
\hline 17 & $\begin{array}{l}\text { How satisfied are you with your ability to } \\
\text { perform daily living activities? }\end{array}$ & 1 & 2 & 3 & 4 & 5 \\
\hline 18 & $\begin{array}{l}\text { How satisfied are you with your capacity for } \\
\text { work? }\end{array}$ & 1 & 2 & 3 & 4 & 5 \\
\hline 19 & How satisfied are you with yourself? & 1 & 2 & 3 & 4 & 5 \\
\hline 20 & $\begin{array}{l}\text { How satisfied are you with your personal } \\
\text { relationships? }\end{array}$ & 1 & 2 & 3 & 4 & 5 \\
\hline 21 & How satisfied are you with your sex life? & 1 & 2 & 3 & 4 & 5 \\
\hline 22 & $\begin{array}{l}\text { How satisfied are you with the support you get } \\
\text { from your friends? }\end{array}$ & 1 & 2 & 3 & 4 & 5 \\
\hline 23 & $\begin{array}{l}\text { How satisfied are you with the condition of your } \\
\text { living place? }\end{array}$ & 1 & 2 & 3 & 4 & 5 \\
\hline 24 & $\begin{array}{l}\text { How satisfied are you with your access to health } \\
\text { services? }\end{array}$ & 1 & 2 & 3 & 4 & 5 \\
\hline \multirow[t]{2}{*}{25} & $\begin{array}{l}\text { How satisfied are you with your means of } \\
\text { transportation? }\end{array}$ & 1 & 2 & 3 & 4 & 5 \\
\hline & & Never & Seldom & Quite often & Very often & Always \\
\hline 26 & $\begin{array}{l}\text { How often do you have negative feelings, such } \\
\text { as blue mood, despair, anxiety, depression? }\end{array}$ & 1 & 2 & 3 & 4 & 5 \\
\hline
\end{tabular}

